\title{
MINIREVIEW
}

\section{Potential therapeutic effects of Resveratrol against SARS-CoV-2}

\author{
L. H. RAMDANI, K. BACHARI
}

Scientific and Technical Research Center in Physico-Chemical Analysis (CRAPC), Tipaza, Algeria

Received May 25, 2020; accepted June 4, 2020

\begin{abstract}
Summary. - Novel Coronavirus COVID-19 or Severe acute respiratory syndrome coronavirus 2 (SARSCoV-2) as well as Severe acute respiratory syndrome coronavirus (SARS-CoV) and Middle East respiratory syndrome coronavirus (MERS-CoV), are human pathogens. Current pandemics of SARS-CoV-2 represents a major health problem worldwide, with over four million cases and more than 300,000 deaths in the world. Development of effective therapy thus became an emergency. This report aims to highlight Resveratrol as possible therapeutic candidate in SARS-CoV-2 infection. The antiviral efficacy of Resveratrol was demonstrated for several viruses, including coronavirus. Resveratrol was shown to mitigate the major pathways involved in the pathogenesis of SARS-CoV-2, including regulation of the renin-angiotensin system (RAS) and expression of angiotensin-converting enzyme 2 (ACE2), stimulation of immune system and downregulation of pro-inflammatory cytokines release. It was also reported to promote SIRT1 and p53 signaling pathways and increase cytotoxic T lymphocytes (CTLs) and natural killer (NK) immune cells. In addition, Resveratrol was demonstrated to be a stimulator of fetal hemoglobin and a potent antioxidant, by trapping reactive oxygen species (ROS). According to these reports, Resveratrol could be proposed as potential therapeutics in the treatment of SARS-CoV-2.
\end{abstract}

Keywords: SARS-CoV-2; Resveratrol; antiviral activity; immune response; ACE2; oxidative stress; HbF

\section{Introduction}

SARS-CoV-2 is a novel coronavirus, which appeared firstly in Wuhan, China, in December 2019 (Zhu et al., 2020). The World Health Organization (WHO) reported on 24 May 2020 five million cases of SARS-CoV-2 infection and more than 300,000 deaths worldwide (WHO). This

E-mail: lamia_pharm@yahoo.fr; phone: +213 (0) 799423134. Abbreviations: ACE2 = angiotensin-converting enzyme-2; CTLs = cytotoxic T lymphocytes; $\mathrm{HbF}$ = fetal hemoglobin; MERS$\mathrm{CoV}=$ Middle-East respiratory syndrome virus; NAD = nicotinamide adenine dinucleotide; NK cells = natural killer cells; RAS = renin-angiotensin system; ROS = reactive oxygen species; SARS-CoV = Severe acute respiratory syndrome coronavirus; SARS-CoV-2 = Severe acute respiratory syndrome coronavirus 2; SIRT1 $=$ sirtuin 1 virus causes high fever, dry cough, headache, muscle pain and pneumonia leading to acute respiratory distress syndrome (ARDS). SARS-CoV-2 is covered with spike surface glycoprotein, which binds to host cells via the receptor angiotensin-converting enzyme 2 (ACE2). Attachment of SARS-CoV-2 to ACE2 would induce a decrease in ACE2 activity, resulting in inflammatory damages and severe form of the disease (Lan et al., 2020).

SARS-CoV-2 infection induces aggressive inflammation initiated by functional exhaustion of immune system with reduction of total number of $\mathrm{NK}$ and $\mathrm{CD} 8+\mathrm{T}$ cells and increased serum levels of pro-inflammatory cytokines (Cao, 2020). It was also demonstrated to be responsible for oxidative stress by causing consumption of nicotinamide adenine dinucleotide (NAD) and accumulation of reactive oxygen species (ROS), which induce pro-inflammatory response (Kouhpayeh et al., 2020). Moreover, SARS-CoV-2 
was reported to attack the heme on the 1-beta chain of hemoglobin, leading to the deterioration of porphyrin. The transport of oxygen and carbon dioxide is thus damaged, resulting in accumulation of poisonous metabolites and development of inflammation in the lung cells (Wenzhong et al., 2020).

Resveratrol (3,4,5-trihydroxy-trans-stilbene) is natural compound belonging to the family of stilbene. This polyphenol is produced in various plants, especially in grapes (Vitis vinifera L.), berries, peanuts, as an antibiotic in response to various stimuli such as stress (Berman et al., 2017).

Resveratrol has been the subject of more than 4,000 studies for its anti-aging, anti-oxidant, anti-inflammatory, anti-viral and cardio-protecting properties(Malaguarnera, 2019) and has been currently tested in clinical trial as potential anticancer treatment (Ko et al., 2017). This report aims to highlight the antiviral and potential therapeutic effect of Resveratrol against SARS-CoV-2.

Resveratrol was described as potent antiviral compound against influenza virus, enterovirus (Campagna et al., 2010) and two species of Coronavirus: Severe acute respiratory syndrome virus (SARS-CoV) and Middle-East respiratory syndrome virus (MERS-CoV) (Lin et al., 2017). Its antiviral-properties would reside in NF- $\kappa B$ inhibition (Holmes-McNary et al.,2000) and activation of both SIRT1 and p53 signaling pathways (Shih et al., 2002). Interestingly, Resveratrol was also found to stimulate immune system by activation of CD8 + T lymphocytes and NK cells, and regulation of CD4+ suppressive T cells (Svajger et al., 2012). This stimulation is mainly related to anti-oxidative and anti-inflammatory properties of Resveratrol (Berman et al., 2017). In addition, Resveratrol could play an important role in regulation of the renin-angiotensin system (RAS) and activation of ACE2 (Moran et al., 2017).

On the other hand, Resveratrol could stimulate the expression of $\gamma$-globin genes and the production of fetal hemoglobin $(\mathrm{HbF})$ in erythroid precursors, leading to increased capacity of hemoglobin to transport oxygen in erythrocytes (Fibach et al., 2012).

Given the urgency to find preventive or curative treatment strategy for SARS-CoV-2 in order to limit the spread of the virus, we attempt in this report to summarize the different molecular mechanisms involved in antiviral activities of Resveratrol and highlight its potential therapeutic effects against SARS-CoV-2.

\section{Antiviral and anti-inflammatory properties of Resveratrol}

Currently, the SARS-CoV-2 pandemic has still no effective remedial drugs or vaccine available. Resveratrol has

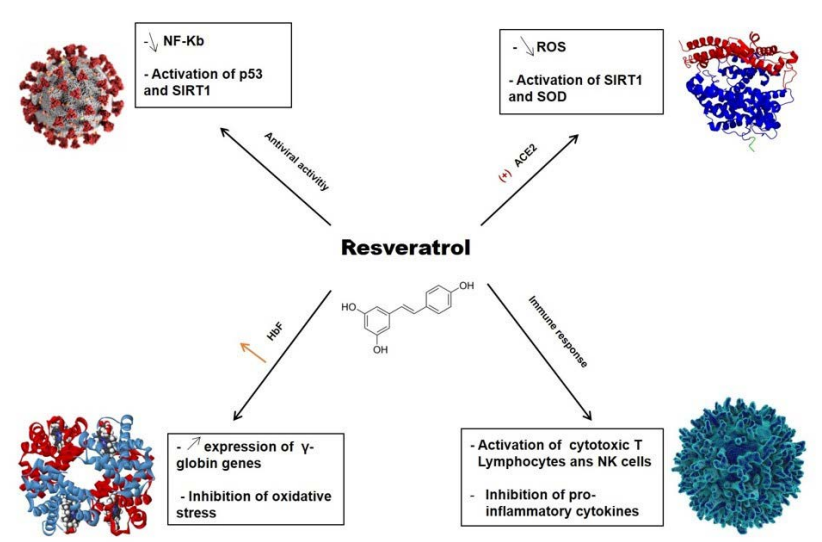

Fig. 1

The major pathways affected by Resveratrol

Antiviral activity, (2) Stimulation of immune system, (3) Activation of ACE2, (4) Production of fetal hemoglobin (Towler, P. et al., J. Biol. Chem. 279, 17996-18007, 2004; Modélisation en 3D du coronavirus SARS-CoV-2. Wikipedia; Haemoglobin-3D-ribbons.Wikipedia; K45300522 www.fotosearch.com).

been shown to affect a wide variety of viruses in vitro and in vivo, including influenza virus (Palamara et al., 2005), herpes simplex virus (HSV) (Docherty et al., 1999), as well as enterovirus (Wang et al., 2004). Interestingly, a strong antiviral activity of Resveratrol has been demonstrated against the coronaviruses SARS-CoV (Li et al., 2006) and MERS-CoV (Lin et al., 2017). The possible antiviral mechanism of Resveratrol seems not to lie in particle inactivation but in the decrease of the translation of late viral proteins (Yusuf et al., 2015). Resveratrol was shown to reduce the inflammation caused by MERS-CoV infection by inhibiting the NF- $\mathrm{B}$ pathway and regulating the production of pro-inflammatory cytokines (Jakus et al., 2013). On the other hand, Resveratrol has been reported to stimulate the activation of p53-mediated apoptosis (Lin et al., 2002) and promote SIRT1 signaling (Chao et al., 2017), two pathways playing a key role in the antiviral activity.

\section{Resveratrol regulates immune system}

SARS-CoV-2 viral infection is regulated by the immune system, in particular by cytotoxic T lymphocytes (CTLs) and NK cells (Zheng et al., 2020). Uncontrolled immune responses and reduction of CTLs and NK were correlated with disease progression. Recent study demonstrated that upregulation of NKG2A expression on NK cells and CTLs in most patients infected with SARS-CoV-2 leads to increased release of pro-inflammatory cytokines (Fu et al., 2020). Pro-inflammatory cytokines such as IL- $1 \beta$, IFN- $\gamma$, IL-6, and TNF- $\alpha$ are important mediators of inflammation 
and their stimulation is associated with lung inflammation observed in SARS-CoV-2 infection (Conti et al., 2020), Interestingly, several in-vitro, preclinical and clinical studies were performed to prove very effective properties of Resveratrol against harmful pro-inflammatory cytokine accumulation (Rafe et al., 2019). Indeed, Resveratrol proved to play an important role in the regulation of immune response and demonstrated strong inhibitory effect on the pro-inflammatory cytokines as IFN- $\gamma$, TNF- $\alpha$ and IL-1 $\beta$, (Zang et al., 2011; Limagne, 2016). Resveratrol was also shown to modulate immune system function by increasing the cytotoxic activity of both CTLs and NK cells, resulting in attenuation of inflammatory responses (Falchetti et al., 2001).

\section{Resveratrol regulates the renin-angiotensin system and enhances ACE2 function}

Recent studies demonstrated the important role of RAS signaling pathway and particularly ACE2 receptor in the entry of SARS-CoV-2 (Hoffmann et al., 2020). ACE2 is expressed in various organs such as the heart, the kidneys, blood vessels and lungs and it function is to convert angiotensin II (which is the main effector molecule responsible for pro-inflammatory activity in the vascular wall) in angiotensin 1-7 (Patel et al., 2016). This latter compound has opposite activity to angiotensin II (Moriguchi et al., 1995). Consequently, the fixation of SARS-CoV-2 in ACE2 receptor results in reduction of ACE2 activity, leading to dysfunction of the RAS and excessive production of pro-inflammatory and pro-oxidant agents causing acute lung injury (Kuba et al., 2006). Resveratrol is known to have many beneficial cardiovascular properties mainly through activation of the sirtuin 1 (SIRT1) (Zordoky et al., 2015). Involved in several cellular processes, SIRT1 plays a protective role in stress response, inflammation and apoptosis regulation (Alcendor et al., 2007). In addition, previous studies demonstrated that activation of SIRT1 and Superoxide Dismutase (SOD) by Resveratrol was associated with increase of ACE2 function and decrease of key markers of inflammation (Clarke et al., 2014; Moran et al., 2017). Therefore, the upregulation of ACE2 by Resveratrol could play an important role in SARS-CoV-2 infection and prevent severe form of the disease.

\section{Antioxidant activity of Resveratrol}

Infection with SARS-CoV-2 results in production of ROS, which induce oxidative stress, resulting in reduction of antioxidant defense and release of pro-inflammatory cytokines (Roche et al., 2020). Depletion of NAD leads also to inhibition of protective protein SIRT1, inducing alteration of immune cell system and accumulation of ROS (Kume et al., 2007). Worsening of oxidative stress results in destructive effects on lipids, proteins and nucleic acids, triggers of a number of human diseases (Rada et al., 2008). Previous reports demonstrated the antioxidant potential and the protective properties of Resveratrol against oxidative stress and aging. Indeed, Resveratrol was demonstrated to scavenge the ROS and increase the expression of antioxidant proteins such as SIRT1. Activation of SIRT1 increases NAD levels and improves mitochondrial function, resulting in regulation of inflammatory diseases and dysfunctional physiological processes (Leonard et al., 2003).

\section{Resveratrol stimulates $\mathrm{HbF}$ production}

More recently it was reported that ORF1ab, ORF10, and ORF3a proteins of SARS-CoV-2 have the ability to attack hemoglobin's heme (Wenzhong et al., 2020), causing destruction of porphyrin and inability of erythrocytes to capture and distribute oxygen effectively (Chowdhury et al., 2017). As reported in experimental animal models and clinical studies in thalassemia patients, Resveratrol enhances the expression of $\gamma$-globin genes and could be a potent antioxidant and $\mathrm{HbF}$ stimulator, leading to improvement of oxygen-binding capacity of hemoglobin. Consequently, increasing production of $\mathrm{HbF}$ by Resveratrol would be proposed as an interesting approach for treating diseases affecting oxygen transport (Fibach et al., 2012).

\section{Conclusion}

In summary, the current report aims to analyze the potential therapeutic efficiency of Resveratrol against SARS-CoV-2. Although the anti-viral properties of Resveratrol in infection with different viruses have already been shown, this report reports for the first time the potential role of the Resveratrol in mitigating the major effects of SARS-CoV-2. Indeed, Resveratrol was reported to downregulate the main signaling pathways of inflammation by increasing activity of both SIRT1 and p53, two proteins involved in anti-viral activities. It was also shown to boost immune system through activation of CTLs and NK cells and regulation of pro-inflammatory cytokines as IL-1 $\beta$, IFN- $\gamma$ and TNF- $\alpha$. Furthermore, Resveratrol was demonstrated to activate ACE2 and reduce oxidative stress causing lung injury in SARS-CoV-2 infection. Regarding these findings, this report suggests that Resveratrol could be used as therapeutic agent or adjuvant against SARS-CoV-2. 
Nevertheless, in order to validate this report, pre-clinical and clinical studies using Resveratrol must be conducted.

Acknowledgments. This report was supported by Scientific and Technical Research Center in Physico-Chemical Analysis (CRAPC).

\section{References}

Alcendor RR, Gao S, Zhai P, Zablocki D, Holle E, Yu X, Tian B, Wagner T, Vatner SF, Sadoshima J, Circ. Res. 100, 1512-1521, 2007. https://doi.org/10.1161/01. RES.0000267723.65696.4a

Berman AY, Motechin RA, Wiesenfeld MY, Holz MK, NPJ Precis. Oncol. 1, 35, 2017. https://doi.org/10.1038/s41698-0170038-6

Campagna M, Rivas C, Biochem. Soc. Trans. 38, 50-53, 2010. https://doi.org/10.1042/BST0380050

Cao X, Nat. Rev. Immunol. 20, 269-270, 2020. https://doi. org/10.1038/s41577-020-0308-3

Chao SC, Chen YJ, Huang KH, Kuo KL, Yang TH, Huang KY, Wang CC, Tang CH, Yang RS, Liu SH, Sci. Rep. 7, 3180, 2017. https://doi.org/10.1038/s41598-017-03635-7

Chowdhury AR, De P, Chakravarty S, Chakravarty A, Int. J. Adv. Res. 5, 1816-1821, 2017.

Clarke NE, Belyaev ND, Lambert DW, Turner AJ, Clin. Sci. 126, 507-516, 2014. https://doi.org/10.1042/CS20130291

Conti P, Ronconi G, Caraffa A, Gallenga CE, Ross R, Frydas I, Kritas SK, J. Biol. Regul. Homeost. Agents. 34, pii: 1, 2020.

Docherty JJ, Fu MM, Stiffler BS, Limperos RJ, Pokabla CM, DeLucia AL, Antiviral Res. 43, 145-155, 1999. https://doi. org/10.1016/S0166-3542(99)00042-X

Falchetti R, Fuggetta MP, Lanzilli G, Tricarico M, Ravagnan G, Life. Sci.70, 81-96,2001. https://doi.org/10.1016/S00243205(01)01367-4

Fibach E, Prus E, Bianchi N, Zuccato C, Breveglieri G, Salvatori F, Finotti A, Lipucci di Paola M, Brognara E, Lampronti I, Borgatti M, Gambari R, Int. J. Mol. Med.29, 974-82, 2012.

Fu Y, Cheng Y, Wu Y, Virol. Sin., 35, 266-271, 2020. https://doi. org/10.1007/s12250-020-00207-4

Hoffmann M, Kleine-Weber H, Schroeder S, Krüger N, Herrler T, Erichsen S, Schiergens TS, Herrler G, Wu NH, Nitsche A, Müller MA, Drosten C, Pöhlmann S, Cell 181, 271-280, 2020. https://doi.org/10.1016/j.cell.2020.02.052

Holmes-McNary M, Baldwin JAS, Cancer Res. 60, 3477-3483, 2000.

Jakus PB, Kalman N, Antus C, Radnai B, Tucsek Z, Gallyas Jr F, Sumegi B, Veres B, J. Nutr. Biochem. 24, 819-23, 2013. https://doi.org/10.1016/i.jnutbio.2012.04.017

Ko JH, Sethi G, Um JY, MK, Arfuso F, AP, Bishayee A, KS, Int. J. Mol. Sci. 18, 2589, 2017. https://doi.org/10.3390/ ijms18122589

Kouhpayeh S, Shariati L, Boshtam M, Rahimmanesh I, Mirian M, Zeinalian M, Salari-jazi A, Khanahmad N, Damavandi MS, Sadeghi P, Khanahmad H, Preprints, 2020.

Kuba K, Imai Y, Penninger JM, Curr. Opin. Pharmacol. 6, 271 276, 2006. https://doi.org/10.1016/j.coph.2006.03.001
Kume S, Haneda M, Kanasaki K, Sugimoto T, Araki S, Isshiki K, Isono M, Uzu T, Guarente L, Kashiwagi A, Koya D, J. Biol. Chem. 282,151-158, 2007. https://doi.org/10.1074/ ibc.M605904200

Lan J, Ge J, Yu J, Shan S, Zhou H, Fan S, Zhang Q, Shi X, Wang Q, Zhang L, Wang X, Nature 581, 215-220, 2020. https://doi. org/10.1038/s41586-020-2180-5

Leonard SS, Xia C, Jiang BH, Stinefelt B, Klandorf H, Harris GK, Shi X, Biochem. Biophys. Res. Commun. 309,1017-1026, 2003. https://doi.org/10.1016/i.bbrc.2003.08.105

Li YQ, Li ZL, Zhao WJ, Wen RX, Meng QW, Zeng Y, Eur. J. Med. Chem. 41, 1084-1089, 2006. https://doi.org/10.1016/j. ejmech.2006.03.024

Limagne E, Lançon A, Delmas D, Cherkaoui-Malki M, Nutrients 8, 280, 2016. https://doi.org/10.3390/nu8050280

Lin HY, Shih A, Davis FB, Tang HY, Martino LJ, Bennett JA, Davis PJ, J. Urol. 168, 748-755, 2002. https://doi.org/10.1016/ S0022-5347(05)64739-8

Lin SC, Ho CT, Chuo WH, Li S, Wang TT, Lin CC., Infectious. Diseases. 17, 144, 2017. https://doi.org/10.1186/s12879017-2253-8

Malaguarnera L, Nutrients 11, pii: E946, 2019. https://doi. org/10.3390/nu11050946

Moran CS, Biros E, Krishna SM, Wang Y, Tikellis C, Morton SK, Moxon JV, Cooper ME, Norman PE, Burrell LM, Thomas MC, Golledge J, Arterioscler. Thromb. Vasc. Biol. 37, 2195-2203, 2017. https://doi.org/10.1161/ATVBAHA.117.310129

Moriguchi A, EA, K, Reilly TM, Walton H, D, Ferrario CM, Hypertension 25, 1260-1265, 1995. https://doi.org/10.1161/01. HYP.25.6.1260

Palamara AT, Nencioni L, Aquilano K, De Chiara, G, Hernandez L, Cozzolino, F, Ciriolo MR, Garaci E, J. Infect. Dis. 191, 1719-1729, 2005. https://doi.org/10.1086/429694

Patel VB, Zhong J, Grant MB, Oudit GY, Circ. Res. 118, 1313-1326, 2016. https://doi.org/10.1161/CIRCRESAHA.116.307708

Rada B, Leto TL, Contrib. Microbiol. 15, 164-187, 2008. https:// doi.org/10.1159/000136357

Rafe T, Shawon PA, Salem L, Chowdhury NI, Kabir F, Bin Zahur SM, Akhter R, Noor HB, Mohib MM, Sagor MAT, Curr. Pharm. Des. 25, 1345-1371,2019. https://doi.org/10.2174 1381612825666190410153307

Roche LD, Mesta F, Arch. Med. Res.51,384-387, 2020.https://doi. org/10.1016/j.arcmed.2020.04.019

Shih A, Davis FB, Lin HY, Davis PJ, J. Clin. Endocrinol. Metab. 87, 1223-1232,2002. https://doi.org/10.1210/icem.87.3.8345

Svajger U, Jeras M, Int. Rev. Immunol.31, 202-222, 2012. https:// doi.org/10.3109/08830185.2012.665108

Wang LX, Heredia A, Song H, Zhang Z, Yu B, Davis C, Redfield R, J. Pharm. Sci. 93, 2448-2457, 2004. https://doi. org/10.1002/ips.20156

Lobo V, Patil A, Phatak A, Chandra N, Pharmacogn. Rev. 4, 118-126, 2010. https://doi.org/10.4103/0973-7847.70902

Wenzhong L, Hualan L, ChemRxiv, 2020.04.27, 2020.

WHO Coronavirus disease (COVID-2019) situation reports, 2020. At https://www.who.int/emergencies/diseases/novelcoronavirus-2019/situation-reports. 
Yusuf A, Hasliza H, Hazilawati H, Mohamed MN, Adv. Virol., $184241,2015$.

Zang N, Xie X, Deng Y, Wu S, Wang L, Peng C, Li S, Ni K, Luo Y, Liu E, J.Virol. 85, 13061-8, 2011. https://doi.org/10.1128/ JVI.05869-11

Zheng M, Gao Y, Wang G, Song G, Liu S, Sun D, Xu Y, Tian Z, Cell. Mol. Immunol. 17, 533-535, 2020. https://doi. org/10.1038/s41423-020-0402-2
Zhu N, Zhang D, Wang W, Li X, Yang B, Song J, Zhao X, Huang B, Shi W, Lu R, Niu P, Zhan F, Ma X, Wang D, Xu W, Wu G, Gao GF, Ta W, N. Engl. J. Med.382, 727-733, 2020. https:// doi.org/10.1056/NEJMoa2001017

Zordoky BN, Robertson IM, Dyck JR, Biochim. Biophys. Acta. 1852, 1155-1177, 2015. https://doi.org/10.1016/j.bbadis. 2014.10 .016 